\title{
3D Modeling Design and Simulation Processing of Complicated Surface Ashtray Based on CATIA Software
}

\author{
Fuman Liu \\ Jilin Engineering Technology College \\ Changchun Jilin China \\ 2277899597@qq.com
}

Keywords: CATIA software; Ashtray; 3D modeling; Design; Simulation processing

\begin{abstract}
This application of CATIA to the design and simulation of complex curved ashtrays and the automatic programming and simulation of CNC machine tools require the design of software such as CATIA. The design and processing of complex parts ashtrays are taken as examples to design a complete 3D modeling and simulation process. Attention problems, automatic programming plays an important role in the processing. Through the research of this article, the people engaged in NC machining recognize the importance of automatic programming and the necessity of using the simulation.
\end{abstract}

\section{Introduction}

Manufacturing is an important pillar of the modern national economy and overall national strength. It is also very important for China, as a large manufacturing country, to master advanced CNC machining technology and programming technology, and automatic programming of software is especially important.[1]

This paper introduces the status of the machining center and its development trend, CNC machining center is a highly efficient, high-precision CNC machine tools, the workpiece in a single fixture can be completed multi-channel processing, this paper on the NC machining center made a brief Is mainly to analyze the machining process of the surface parts, and to elaborate the principle of the process route of such parts, the compensation of the tool radius and the processing method, and put forward the automatic programming method of this part. In order to determine the reasonable machining path Route provides a basis for mastering the structure of the machining center and processing technology. Then use the software for simulation and CNC automatic programming, and finally use the data line to generate the $G$ code program is transmitted to the machining center, processed to meet the accuracy requirements of the parts.[2]

\section{Analyze the Part Drawing and Determine the Installation Reference}

Ashtray shown in Figure, taking into account the structure and shape of the parts, as well as the actual machining of machine tools used in the processing characteristics, select the bottom part of the fixture for the positioning surface, the fixture with tiger pliers.

Considering the parts of the length, width and height of the maximum size were $98 \mathrm{~mm}, 98 \mathrm{~mm}$, $22.2 \mathrm{~mm}$, so choose the blank size of $105 \mathrm{mmX} 105 \mathrm{mmX} 25 \mathrm{~mm}$ cube. Also taking into account the use of CNC machining centers of processing capacity and stiffness, parts surface roughness, dimensional accuracy, and so require a higher, so the selected parts of the blank material is aluminum, because the aluminum machining performance is good and not Need to do heat treatment processing.[3]

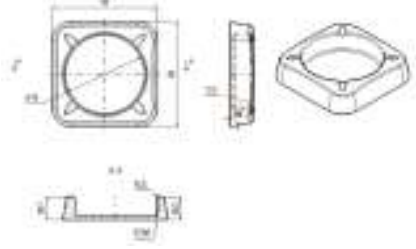

Figure 1. Ashtray parts drawings 


\section{CATIA Software Three-dimensional Design}

Establish Processing Ashtray Model, Use CATIA software to make three-dimensional threedimensional ashtray, the stereo image is saved as igs format, and then use the CAXA manufacturing engineer to open this file before use. Three-dimensional map production process:[4]

Click to create a generative shape design, set the hidden keys and shortcuts according to personal habits. In order to ensure that changes at any time, it is best to establish more than a few geometric graphics. Change the geometry set to the appropriate name, for example: Bottom, Side, Top, Chamfer, etc. This can find the corresponding location faster. Create a sketch in the XY plane, enter the sketch editor, draw a square, and fill the square.[5]

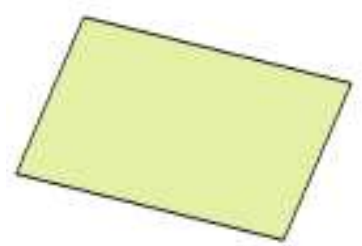

Figure 2. Sketch padding

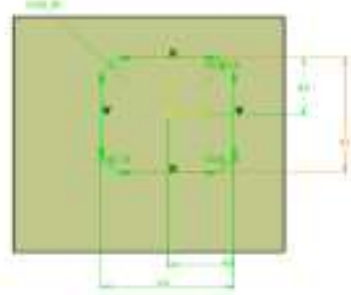

Figure 3. Bottom sketch

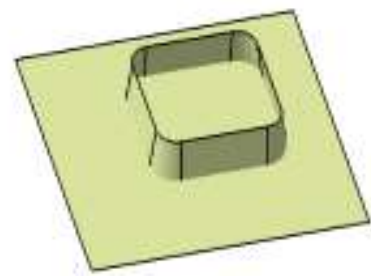

Figure 4. Side structure

Create a point in the fill surface, as the midpoint of the part, use this point to create a coordinate system, fill the surface as a sketch support surface, into the sketch editor, draw the bottom surface of the part, first draw a square, the constraint side length of $98 \mathrm{~mm}$, Chamfer to get bottom sketch.

Click the Sweep command, with the sketch of the bottom surface as the guide line and the fill surface as the supporting surface for scanning, to obtain the side graphic. Move the pad upward by $22.6 \mathrm{~mm}$ as a support surface for the upper surface.[6]

Offset the center point $255 \mathrm{~mm}$ downwards and center the ball to create a $280 \mathrm{~mm}$ diameter ball. With the fill surface translated $3 \mathrm{~mm}$ upwards and the offset surface as the sketch support surface as a sketch, draw a circle with a radius of $38 \mathrm{~mm}$ and stretch the circle to the bottom of the outline of the ashtray.[7]

Contour surface rendering is completed, the next is to trim and chamfer each surface, the beginning of the fill surface and sweep the surface to be trimmed, get trim A.

The outline of the ashtray to draw complete, but also need to be able to place a few slots of smoke, the support surface of the upper surface offset $1.5 \mathrm{~mm}$ upward to the surface of a sketch for drawing a 45 degrees straight through the ashtray, with a straight line Guide line, the offset surface for the support surface to sweep, get a tube A.[8]

Use the same method to draw a tube of -45 degrees B, use the trim command, the pruning $C$ and the tube A pruning, to be trimmed $\mathrm{D}$. Trim $\mathrm{D}$ and tube $\mathrm{B}$ to obtain trim $\mathrm{E}$

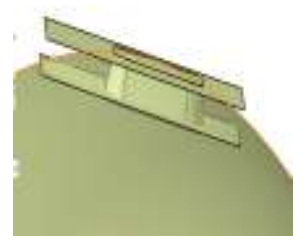

Figure 5. Ashtray on the surface

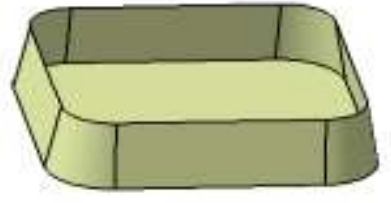

Figure 6. Trim A

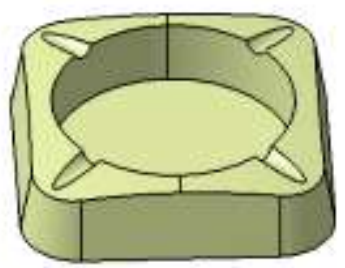

Figure 7. Trim E

Trim E trim, you can get the ashtray body. Chamfer is best to use variable fillet, in order to change the same line in different locations. Now just a slice structure, you need to change the interface, go to the part design interface, click the closed surface, the interior of the chip structure to be closed, become a solid, ashtray design is completed. 


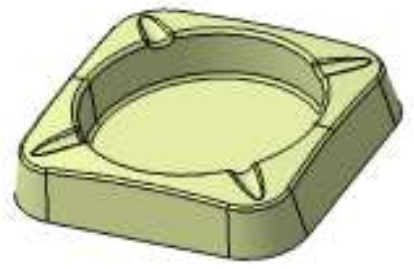

Figure 8. Ashtray

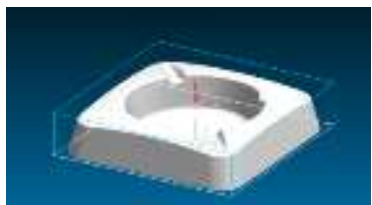

Figure 9. Machining the origin coordinate system

\section{Ashtray Simulation Processing}

Establish Processing Coordinate System, When using software programming, the center of the blank upper surface should be confirmed as the origin of the left system during machining. This will facilitate the tool setting and the $\mathrm{Z}$ axis of the machining coordinate system and the $\mathrm{Z}$ axis direction of the machine coordinate system must be the same.

Select the Amount of Cutting Three Elements, As the parts of the rough is the choice of aluminum, so its cutting processing performance is good, the use of processing machine tools used is $\mathrm{CNC}$ machining centers, taking into account the actual use of vertical machining center performance and processing characteristics, the back to eat the amount of knife The maximum value of $2 \mathrm{~mm}$, but also due to the machined parts of the surface roughness of the higher *, so the need for roughing, finishing, so roughing, select the back to eat the amount of knife MID 1.0mm, fine The finishing allowance selected for machining is $0.1 \mathrm{~mm}$. In addition, since the feed rate of the machine tool is $100 \mathrm{~mm} / \mathrm{min}$, in order to improve the machining efficiency, the feed rate in the profile direction (ie, FFP1) is selected to be $100 \mathrm{~mm} / \mathrm{min}$ in the roughing process and the feed amount in the depth direction $50 \mathrm{~mm} / \mathrm{min}$. In finishing, the feed for the profile direction (ie FFP1) is selected to be 80 $\mathrm{mm} / \mathrm{min}$ and the feed to the depth (ie FFD) to $40 \mathrm{~mm} / \mathrm{min}$ for surface and contour machining accuracy.[9]

As the processing of parts of aluminum, its cutting performance, and the selected amount of feed and back to eat the amount of knife are relatively small, so the inspection table reference, the cutting speed can be made larger, so the choice of cutting speed $80 \mathrm{~m} / \mathrm{min}$. Therefore, when the choice of + milling cutter milling parts, the spindle speed.

Optional roughing spindle speed 3000r / min, finishing spindle speed 3000r / min.

The choice of cutting three elements as shown in table 1.

Parts CNC Machining Tool Card, Milling the surface of the workpiece, the use of face milling cutter, in order to improve the accuracy of surface machining parts to avoid knives in the knives produced at the junction, so the choice of the tool diameter should be as large as possible, so milling the surface of the workpiece When the choice of face cutter diameter $50 \mathrm{~mm}$. When milling a square profile, the diameter of the selected end mill is $10 \mathrm{~mm}$ for milling the inner profile due to the inner profile (the inner profile has a radius of $40 \mathrm{~mm}$ ). Finishing the contour, the choice of $6 \mathrm{~mm}$ diameter ball end milling machine for processing. The tool material is carbide, good rigidity, to meet the processing stiffness requirements., Parts CNC machining tool card as follows:[10]

Table 1 Cutting three elements

\begin{tabular}{|l|l|l|l|l|}
\hline & $\begin{array}{l}\text { speed of } \\
\text { mainshaft } \\
\end{array}$ & \begin{tabular}{l} 
(r/min) \\
\cline { 3 - 4 }
\end{tabular} & Feed & \multirow{2}{*}{$\begin{array}{l}\text { The cutting } \\
\text { depth }(\mathrm{mm})\end{array}$} \\
\cline { 3 - 5 } Rough cutting & 3000 & 100 & 50 & 1.0 \\
\hline fine machining & 3000 & 80 & 40 & 0.1 \\
\hline
\end{tabular}


Table 2 NC cutting tool card

\begin{tabular}{|c|c|c|c|c|c|}
\hline $\begin{array}{l}\text { Product name or } \\
\text { code name }\end{array}$ & & Part name & & Part drawing number & \\
\hline Serial number & $\begin{array}{l}\text { Tool } \\
\text { number }\end{array}$ & $\begin{array}{l}\text { Tool specification and } \\
\text { name }\end{array}$ & NUM & Machined surface & Remarks \\
\hline 1 & T01 & $\varphi 50$ Face milling cutter & 1 & $\begin{array}{l}\text { Rough finishing of the } \\
\text { upper surface of a part }\end{array}$ & \\
\hline 2 & T02 & $\varphi 10$ butt mill & 2 & $\begin{array}{l}\text { The rough outline of } \\
\text { the hole }\end{array}$ & \\
\hline 3 & T03 & $\Phi 6$ butt mill & 2 & \begin{tabular}{|l|} 
Surface finishing \\
rough finishing
\end{tabular} & \\
\hline
\end{tabular}

Simulation Processing, Select the rough, cutting tools and processing parameters, simulation processing, optimization parameters, you can get the following simulation diagram, simulation software will generate the following tool path.

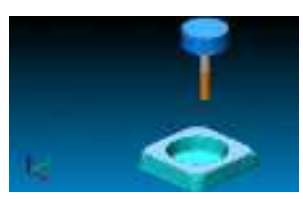

Figure 10. Rough outline

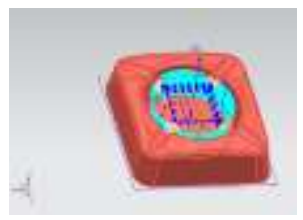

Figure 11. Fine milling outline Figure 12. Fine milling the inner contour

After finishing the inner contour, the need for finishing the outer contour to ensure accuracy, fine milling trajectory shown in Figure

Because it is a machining center, it can be done in one clamping. In order to ensure the accuracy of the upper surface, the upper surface is separately rough-milled and finished.

\section{Conclusion}

The application of CATIA to the design and simulation of complex curved ashtrays has been summarized. A complex shape processing program with the advantage of automatic programming has been summarized. A complete machining process and numerical control program have been prepared by using complex parts as an example. Plays an important role. Through the research of this article, the people engaged in CNC machining recognize the importance of automatic programming and the necessity of using automatic programming.

In this paper, CATIA software for automatic programming of complex parts of the design and implementation of NC programming for complex parts of the automatic programming design and simulation with reference value.

\section{References}

[1] Guangzhen, Lu Jianxiang, NC technology and programming [M]. Beijing: Peking University press, 2015.08

[2] Meng Lingxia, Zhang Zhi, numerical control technology training course [M]. Beijing: National Defence Industry Press, 2014

[3] Tang Wenxian, introduction and improvement of CNC machining process [M]. Beijing: China Machine Press, 2013

[4] $\mathrm{Wu}$ Zhiguo, Huang Yunlin, and so on, CNC lathe programming 80 cases: the essence of the [M]. Beijing: Chemical Industry Press, 2014 (in Chinese)

[5] Lv Binjie, Gao Changyin, Zhao Wen (FANUC.SIEMENS), CNC lathe programming example of the essence of [M]. Beijing: Chemical Industry Press, 2011

[6] Ni Xiangming, CNC machine tools and CNC machining technology [M]. people's Posts and Telecommunications Press, 2011 
[7] Sun Xingwei, Xue Xiaolan, FANUC programming and processing of CNC machine tools [M]. Beijing: China Water Conservancy and Hydropower Press, 2015 (in Chinese)

[8] Yunjie Zhang、 Lijian Hao, CATIA V5-6 R2014 foundation design case.Tsinghua University Press, 2015.06

[9] Yunjie Zhang, Yunjing Zhang, CATIA V5 from to master.Tsinghua University Press, 2013, R21, entry, the

[10]Zhan Yi, CATIA V5R20 CNC machining tutorial [M]. Beijing: China Machine Press, 2013. 